SESSION III

Chairman: Professor J. H. MidDlemiss

\title{
Cartilage hair hypoplasia
}

\author{
D. C. Siggers \\ M.B., B.S., M.R.C.P. \\ J. B. BURKE \\ B. MORRIS \\ F.R.C.P. \\ M.D., F.R.C.P., D.C.H. \\ I. C. S. NORMAND \\ D.M., F.R.C.P. \\ J. M. TANNER \\ M.D., Ph.D., D.Sc., F.R.C.P. \\ D. A. J. Williamson \\ M.D., F.R.C.P., D.C.H. \\ Department of Child Health, University of Southampton, East Wing, Southampton General Hospital
}

\begin{abstract}
Summary
Six cases of cartilage hair hypoplasia from five kindreds are described. They demonstrate variation in the expression of clinical features such as sparsity of hair, hair calibre, radiological changes, short stature and the extent of the disproportion between sitting height and stature.
\end{abstract}

CARTILAge hair hypoplasia is one of a group of metaphyseal chondrodysplasias. It is distinguished from the others by the eponymous qualification'McKusick type'. In 1965 McKusick published a paper describing seventy-seven cases amongst the Amish communities of North America. It is an autosomal recessive condition. McKusick et al. (1965) described the syndrome in the following terms: "the dwarfism is of the short limbed variety. The hands are short and pudgy, the fingers loose jointed and the finger nails are short, but of nearly normal width. The elbow joints do not fully extend, Harrison's grooves can often be seen in the thorax and the head hair is sparse, fine and silky in most persons and its diameter is reduced. Histology of the costochondral junction shows a paucity of cartilage cells which fail to be aligned in orderly cell columns at the growth line'. He concluded that failure of cartilage growth was the main fault.

Amongst the Amish community the incidence of

Correspondence: Dr D. C. Siggers, Department of Child Health, University of Southampton, Centre Block, Southampton General Hospital, Southampton. cartilage hair hypoplasia is about 1.5 per thousand persons. Outside the Amish community this disorder is rare (McKusick, 1972). Since McKusick's description in 1965 only one definite case, so far as the authors know, has been diagnosed in Britain, that being published by Boothby and Bower in 1973, and this was a typical case. Before that time others may have been reported under different names and since then, of course, further cases may have been diagnosed but not published.

\section{Patients studied}

The authors have observed six cases in southern England and these are the basis of their experience, brief details being shown in Table 1. See Figs 1-6.

\section{Radiological features}

The main abnormalities are the metaphyseal changes, particularly at the knees and ankles (Fig. 7) and mildly at the hips, which distinguish the disorder from other members of this group. These changes diminish with advancing age and in a child of 11.75 years of age (Fig. 8) were seen to be relatively minor. There is some discrepancy in bone age between the bones of the hand and the wrist, e.g. in the hands of a child aged 5 years 5 months, the digital bones had an age of 4 years and 2 months, whilst the carpal bones were only 3 years and 2 months (Fig. 9). One could also note shortened and wide phalangeal metaphyses with other metaphyseal changes. 
TABLE 1 .

\begin{tabular}{|c|c|c|c|c|}
\hline Case no. & Habitat & Sex & $\begin{array}{c}\text { Age } \\
\text { (years) }\end{array}$ & $\begin{array}{l}\text { No. of standard } \\
\text { deviations below the } \\
\text { mean height }\end{array}$ \\
\hline 1 & Reading & $\mathbf{F}$ & $3 \cdot 25$ & $5 \cdot 8$ (Fig. 1) \\
\hline 2 & Luton & $\mathbf{M}$ & $6 \cdot 75$ & (Fig. 2) \\
\hline 3 & Southampton & $\mathbf{F}$ & $5 \cdot 5$ & (Fig. 3) \\
\hline 4 & Southampton & $\mathbf{F}$ & $11 \cdot 75$ & 3.75 (Fig. 4) \\
\hline 5 & Cambridge & $\mathbf{M}$ & $11 \cdot 25$ & 3.8 (Fig. 5) \\
\hline 6 & Cambridge & $\mathbf{F}$ & $9 \cdot 75$ & (Fig. 6) \\
\hline
\end{tabular}

Cases 5 and 6 were siblings.

The hips show relatively little abnormality. The vertebrae are described as small, more so in the A-P diameter and are said to be columnar. Changes are also seen in the upper and lower end plates of the vertebrae, tending to appear in adolescence. The lesions may resemble Schmorl's nodes and may also appear in the adult. The vertebrae are an exception to the general rule that the radiological changes diminish with advancing age.

\section{The hair}

McKusick et al. (1965) figured both normal hairs and those of patients with cartilage hair hypoplasia, giving a graph depicting the differences in hair calibre and its variation in his patients. He also, in his Amish patients, noted that the hair, although sparse in many, may not show marked deficiency in others. This point was confirmed in the present patients (e.g. Figs 2 and 3). Nevertheless, the hair is fine and microscopically typical. However, on comparing the calibre ranges of the 97th to 3 rd centiles for normal hair and that from patients with this disorder, some overlap was noted.

The absence of any pigmented core in the hair is also stated to typify this condition. But in one of the patients, a boy with the disorder, several hairs were examined and found to have both a normal diameter and a pigmented core (Fig. 10). His mother, however, stated that she had observed the presence of several unusually dark hairs and provided these as a sample when requested to do so, thinking that they were rare and maybe interesting. Thus there may be, in fact, a certain degree of variation within, as also between, individual patients. The demonstration of a relatively wide hair diameter with a pigment core present therefore does not by any means exclude the diagnosis.

An Amish girl, with darker abundant hair was in fact amongst McKusick's later patients. He stated: 'in most cases, the dwarfed person's head hair is sparse, fine and silky, but the light colour is not such a consistent feature as the others and as the individual ages, the hair becomes darker. Since the pigment core is correlated with hair colour, the lack of a pigmented core may be a function of the small hair diameter'.

\section{Stature}

McKusick's original patients were stated to vary in height between 102 and $156 \mathrm{~cm}$. One hundred and fifty-six centimetres is not particularly short and height, like hair calibre, is another feature which displays considerable phenotypical variation. This was the height range within the Amish community and so there is not likely to be genetic heterogeneity.

It is interesting that in the original seventy-seven Amish patients, McKusick found amongst the sibships only $70 \%$ of the expected number of affected sibs. He ruled out several possible explanations," concluding that this discrepancy was one of reduced gene penetrance. He also noted one family with both parents homozygous for cartilage hair hypoplasia whose three children were at first thought to be normal, but in whom characteristic radiological changes were eventually demonstrated despite their normal stature. It is moreover striking to compare this recessive disorder with considerable phenotypical variation, not supposed to occur in recessives, with achondroplasia which, for a dominant condition, has surprisingly little. The heights of the author's six patients have ranged from 3.5 to 6.0 s.d. below the mean.

\section{The body proportions}

McKusick emphasizes that the dwarfism is short limbed. Two girls of the present six patients were charted for sitting height against total height and were at the 97th centile, as were also the various recorded heights of one boy. The brother and sister from Cambridge were at the 50th centile for a younger age group. So if these two sibs were not of disproportionate stature, as they were at the 50th centile, did they have cartilage hair hypoplasia? They were reported by Savage and Tizard (1972) as having a variant of cartilage hair hypoplasia. One might perhaps deduce that each child has equally 


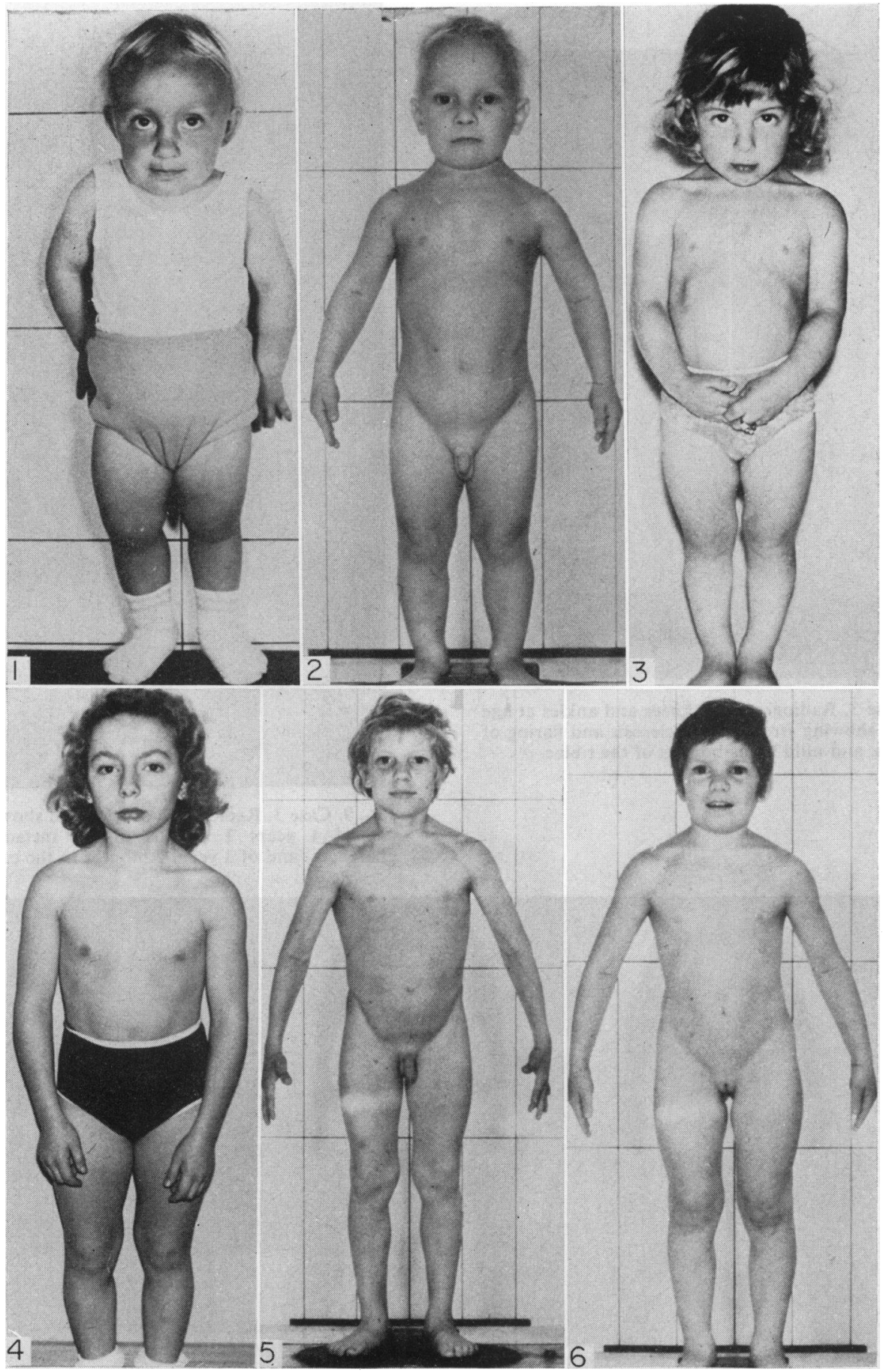

Fig. 1. Case 1. Age 3.25 years; height, $75 \mathrm{~cm}$.

Fig. 3. Case 3. Age 6 years; height, $87 \mathrm{~cm}$.

FIg. 2. Case 2. Age 6.75 years; height, $87 \mathrm{~cm}$.

Fig. 4. Case 4. Age 11.75 years; height, $122.5 \mathrm{~cm}$.

Fig. 5. Case 5. Age $11 \cdot 25$ years; height, $118 \mathrm{~cm}$.

FIG. 6. Case 6. Age 9.75 years; height, $111 \mathrm{~cm}$. 


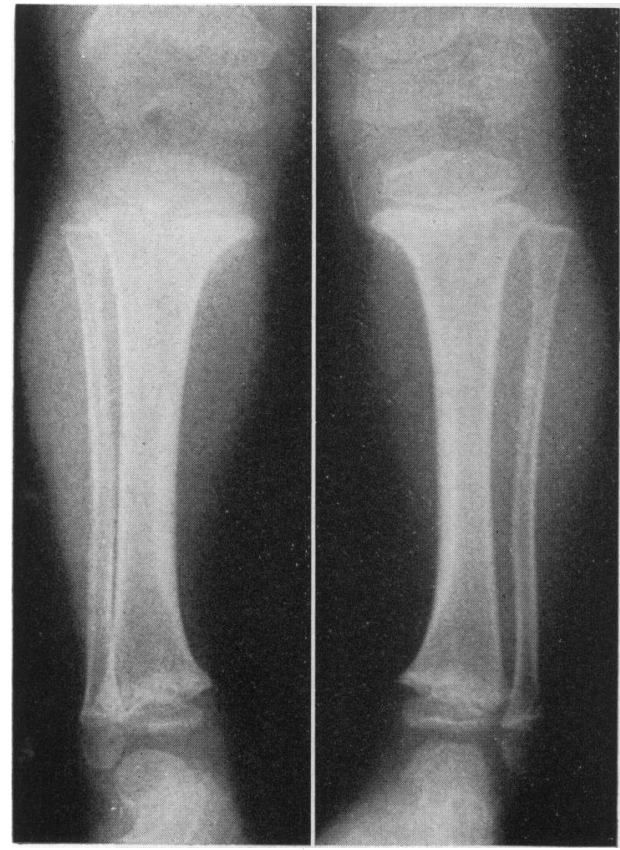

FIG. 7. Case 3. Radiographs of knees and ankles at age 4.25 years showing irregularity, sclerosis and flaring of metaphyses, and mild varus bowing of the tibiae.

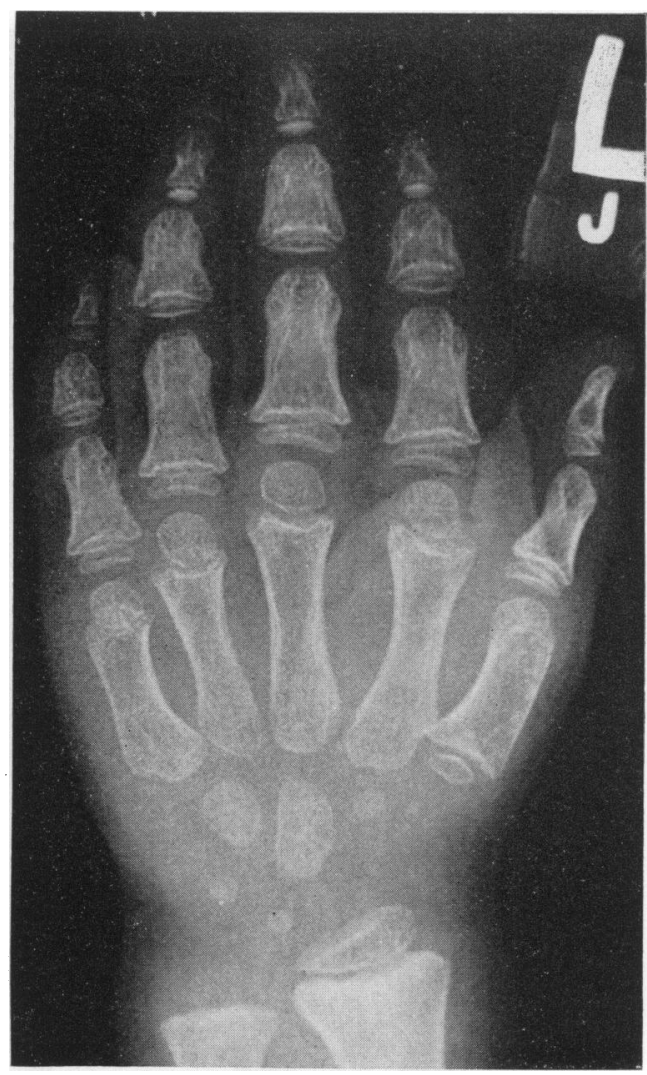

Fig. 9. Case 3. Radiograph of left hand showing a bone age of 4 years 2 months in the metacarpals and phalanges, and of 3 years 2 months in the carpals.

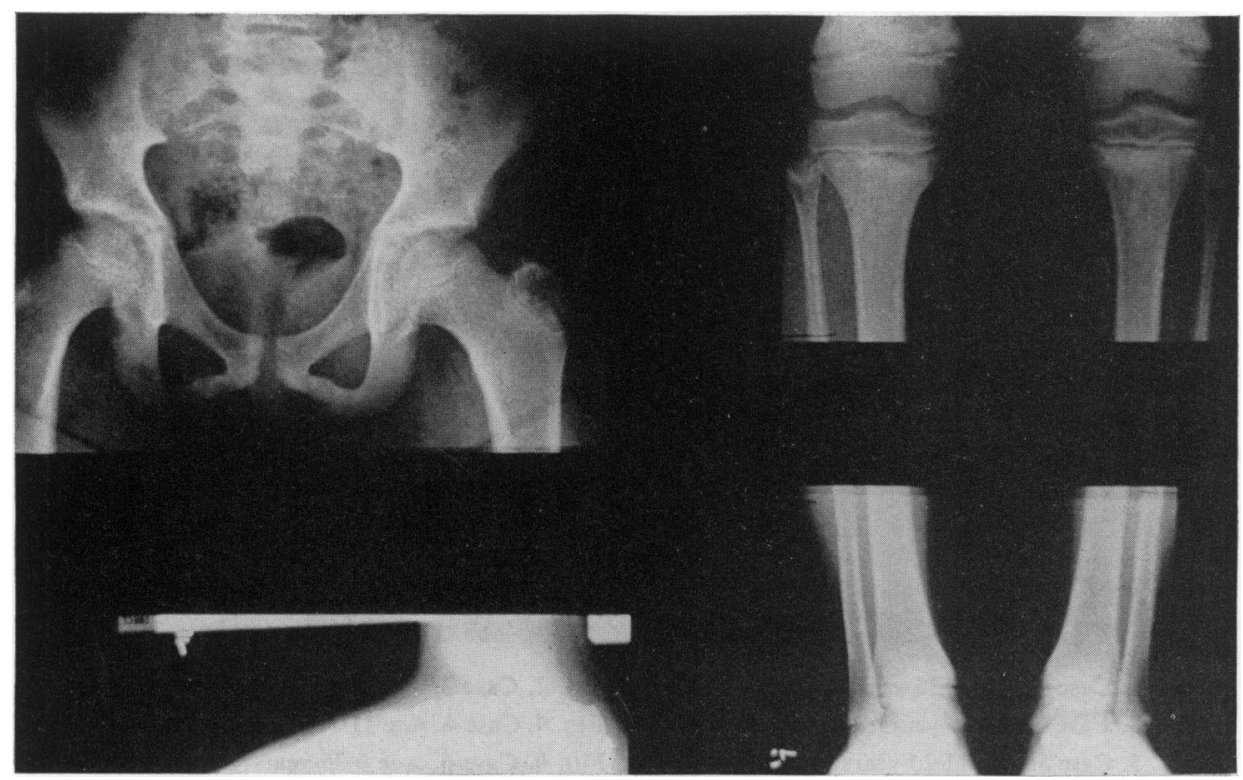

Fig. 8. Case 4. Radiographs of hips, knees and ankles at age 1175 showing mild metaphyseal changes of lower femur, upper and lower tibia and fibula. 


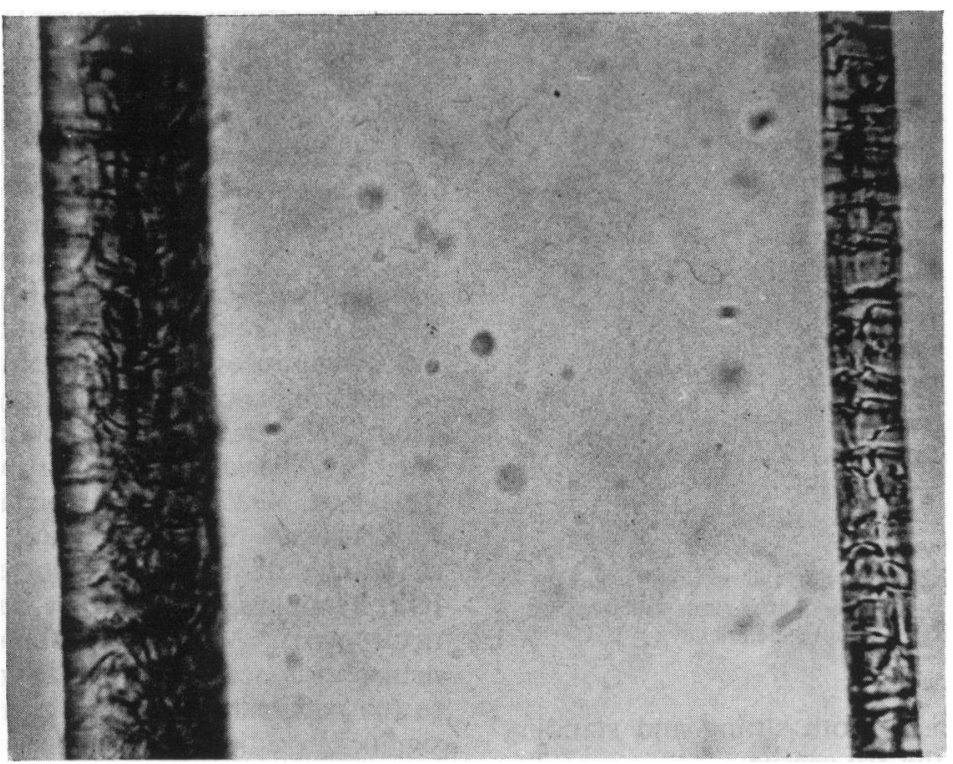

Fig. 10. Case 2. Photomicrograph of two hair shafts (diameters - left $-33 \mu \mathrm{m}$ : right $-16 \mu \mathrm{m})$, to show the range of calibres in a single patient.

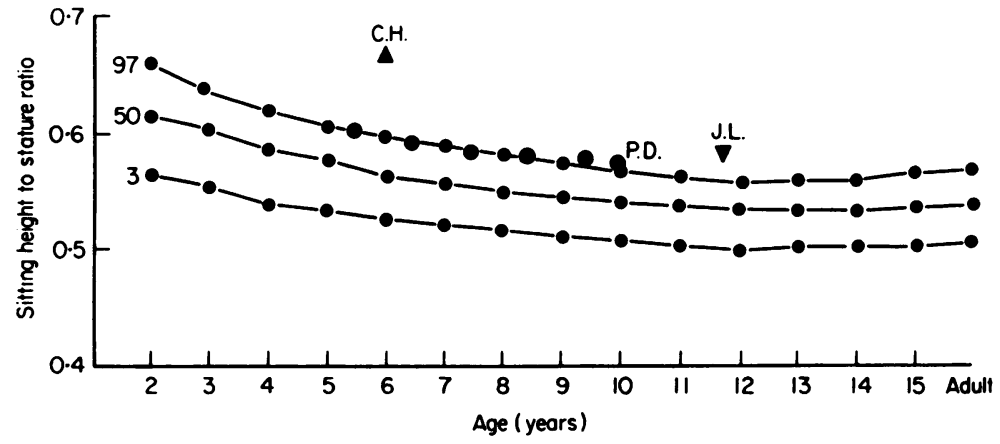

Fig. 11. Centile chart showing the sitting height to stature ratio of case 3 (C.H.), case 6 (P.H.) and case 4 (J.L.) (girls) in relation to their ages.

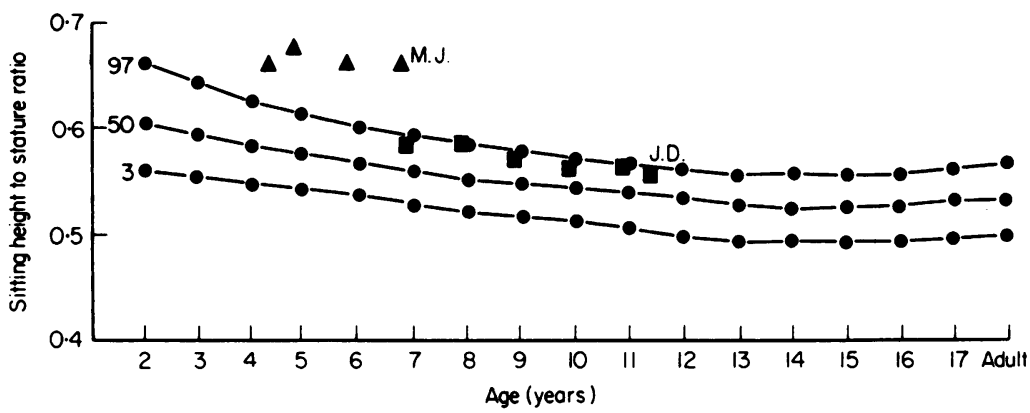

FIg. 12. Centile chart showing the sitting height to stature ratio of case 2 (M.J.) and case 5 (J.D.) (boys) in relation to their ages. 


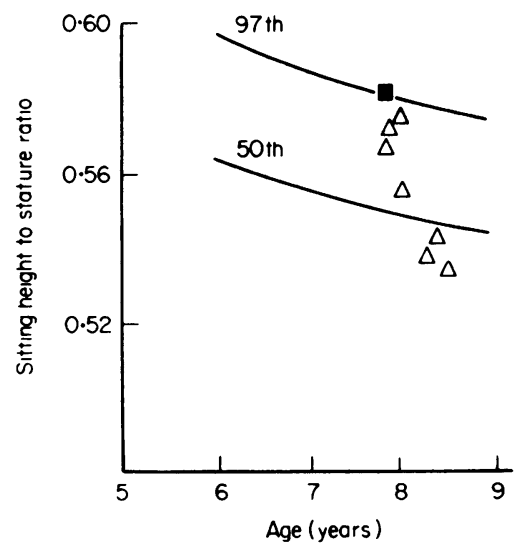

Fig. 13. Centile chart showing the sitting height to stature ratio of case $5(\square)$, compared with five boys of similar age with growth hormone-deficiency $(\triangle)$.

proportioned dwarfism, both sitting and standing height being below the 3rd centile.

Using other charts the sitting height/total height ratios were calculated for these two sibs according to their age (Figs 11 and 12). It must be remembered that if an older person is proportionately short in both total stature and limbs, the data may be superimposed upon those of a younger child, i.e. a 7-year-old upon a 2-year-old. When plotted accordto age, the data for the girl P.D. (case no. 6) were in fact on the 97th centile for the age-related ratio (Fig. 11), indicating that she did have disproportion, although not so clearly defined as the other two girls (cases nos 3 and 4). Similarly, her brother (case 5) was found to be at the 97th centile (Fig. 12).

Clearly an age-related body-proportions chart is mandatory. Comparing with similar data for growth hormone-deficient children of the same age the boy of the sib pair (case no. 5) with cartilage hair hypoplasia was noted to be at the 97th centile and the growth hormone-deficient children above and below the 50th, some being close to case no. 5 (Fig. 13). It appears likely, therefore, that there may be some overlap between some patients with cartilage hair hypoplasia and others with so-called proportionate dwarfism.

\section{Differential diagnosis}

This is not discussed here in full detail since it is covered by Professor Spranger (1977) in his paper on metaphyseal chondrodysplasias in this symposium. There is, however, need to stress the variation in the phenotypic expression of cartilage hair hypoplasia. It is also necessary to mention its differentiation from another disorder with several names-one being 'pancreatic deficiency neutropenia syndrome' (Burke et al., 1967). This has some features in common with cartilage hair hypoplasia but nevertheless they are clearly different conditions. Both are autosomal recessive. No alteration of hair is reported in pancreatic deficiency neutropenia syndrome. The stature is disproportionate in cartilage hair hypoplasia and proportionate in pancreatic deficiency neutropenia. Coeliac syndrome, with no deficiency of the pancreatic enzymes, and Hirschprung's disease have been reported in cartilage hair hypoplasia but not in pancreatic deficiency neutropenia. Metaphyseal chondrodysplasia and neutropenia occur in either disorder but, in contrast to the pancreatic deficiency neutropenia syndrome, significant radiological changes in the upper femur and humerus are absent in cartilage hair hypoplasia.

To conclude, cartilage hair hypoplasia is a recessively inherited condition with considerable phenotypical variation in the hair, height and bodily proportions. Should one see a short child in one's clinic, one should not immediately call for an insulin, a Bovril or an arginine tolerance test, an intestinal biopsy and so on-one need but ask for radiological examination of a knee, which will suggest the correct diagnosis.

\section{References}

BoothBy, C.B. \& Bower, B.D. (1973) Cartilage-hair hypoplasia. Archives of Disease in Childhood, 48, 918.

Burke, V., Colebatch, J.H., Anderson, C.M. \& Simons, M.J. (1967) Association of pancreatic insufficiency and chronic neutropenia in childhood. Archives of Disease in Childhood, 42, 147.

McKusick, V.A. (1972) Heritable Disorders of Connective Tissue, 4th edn. C. V. Mosby Co., St Louis.

McKusick, V.A., Eldridge, R., Hostetler, J.A., RuangWIT, U. \& Egeland, J.A. (1965) Dwarfism in the Amish. II. Cartilage hair hypoplasia. Bulletin of the Johns Hopkins Hospital, 116, 285.

Savage, M.O. \& Tizard, J.P.M. (1972) Metaphyseal dysplasia in siblings: A variant of cartilage-hair hypoplasia. Proceedings of the Royal Society of Medicine, 65, 727.

SPRANGER, J.W. (1977) Metaphyseal chondrodysplasia. Postgraduate Medical Journal, 53, 480. 